\title{
AVAnCES EN EL ANÁLisis DE CERÁMICA y PIGMENTOS EN ARQueOlogía (PARTE 2): UNA INTROdUCCIÓN
}

\author{
Isabelle Druc \\ Departamento de Antropología, University of Wisconsin-Madison \\ icdruc@wisc.edu \\ Jalh Dulanto \\ https://orcid.org/0000-0003-0528-1860 \\ Departamento de Humanidades, Pontificia Universidad Católica del Perú \\ jdulant@pucp.pe
}

Este segundo volumen de Avances en el análisis de cerámica y pigmentos en arqueología se abre con un artículo de Mayra Carmen Castillo y Krzysztof Makowski sobre la cerámica provincial inca como expresión de estatus en la población mitmaquna de Pueblo Viejo-Pucará, en el valle bajo de Lurín, durante el Horizonte Tardío. En esas páginas los autores abordan el problema de las imitaciones locales de los estilos imperiales inca. Los fragmentos de cerámica analizados provienen de dos residencias palaciegas y el análisis mediante microscopía digital se enfoca en la pasta y los acabados, en comparación con estudios previos sobre la procedencia de las fuentes de arcilla con LA-TOFICP-MS y la identificación de los diferentes alfares presentes en el sitio. Los autores examinan la relación entre los estilos inca y locales y las interpretaciones que damos a los datos acerca de las identidades cultural, étnica y política del productor y el usuario de estas vasijas. De modo sutil, ponen en relieve el proceso de construcción de identidades nuevas en el contexto estudiado.

Jalh Dulanto, Isabelle Druc, Alejandro Rey de Castro, Laure Dussubieux y Enrique Guadalupe presentan los resultados de los análisis por LA-ICP-MS de fragmentos de vasijas de cerámica de Puerto Nuevo y de muestras de arcillas de los valles de Pisco e Ica, en la costa sur del Perú, en un esfuerzo por identificar las fuentes de arcilla explotadas por los alfareros de dichos valles durante el primer milenio antes de Cristo. Cruzan los resultados estadísticos del análisis químico, mineralógico, y estilístico para ofrecer una visión compleja de los patrones de producción, circulación y consumo de estos bienes en esta época.

Francesca Fernandini, Alejandro Trujillo Quinde, Mirian Mejía Santillán y Silvana Cuadros Gómez presentan el análisis de diecisiete muestras de cerámica del sitio arqueológico Cerro de Oro (550-850 d.C.) —ubicado en el valle de Cañete, en la costa central — utilizando las técnicas de microscopía Mössbauer y la difracción de rayos-X para cinco de las muestras, para confirmar la composición de la arcilla. Se trata de cerámica típica y de algunos tiestos atípicos, y por tanto se discute su posible origen foráneo. También analizan fuentes de arcilla tratando de identificar aquellas que posiblemente estuvieron en uso en esos tiempos.

Cecilia Frigolé, Camila Riera-Soto, Andrew Menzies, Monserratt Barraza, Anahí Benítez y Diego Winocur abordan la caracterización de la cerámica de la provincia de Mendoza, en el centrooeste argentino mediante la petrografía y QEMSCAN (Quantitative Evaluation of Minerals by Scaning Electron Microscopy), técnica introducida ya en el primer volumen. Un interés particular 
de este estudio reside en la comparación entre estas dos técnicas para el análisis de la cerámica arqueológica, demostrando el poder de cada una y su complementariedad, tanto en el análisis de ciertos componentes de la pasta que se identifican difícilmente con la petrografía, como en la interpretación de los datos facilitada por esta. Mediante ambas técnicas los autores llegan a identificar grupos de pastas de procedencia diversa, vinculando su composición con distintos marcos geológicos.

Javiera Gajardo examina la variabilidad de la cerámica pintada y con engobe de El Vergel, en la Araucanía del Sur de Chile, durante el periodo entre 1000 y 1550 d.C. Examina la manufactura de este alfar bajo el paradigma de la cadena operativa, con una mirada particular a la elección de los pigmentos para las pinturas y engobes. Utilizando la técnica de LA-ICP-MS analiza la cerámica de cinco sitios domésticos de diferentes áreas geográficas, identificando «recetas» para estos pigmentos y grupos de composición para las pinturas y engobes, y pinturas que se pueden vincular a ciertos ejes geográficos. Sobre la base de los resultados de este análisis, la autora reflexiona sobre las posibilidades de circulación de las recetas, pigmentos o las mismas piezas.

Valeria Herrera y Verónica Acevedo nos ofrecen una metodología para la conservación y gestión de los pigmentos arqueológicos y la generación de base de datos. Presentan la técnica de microestratigrafía y los protocolos de muestreo que se emplean, y muestran casos de cerámica prehispánica del noroeste argentino en las que se han aplicado. Siendo Herrera conservadora, se considera también las normativas de conservación de bienes culturales a nivel internacional y en Argentina.

Breanna Reiss, Michael Spilde y Eric Peterson presentan los resultados de los análisis químico y mineral de la composición del pigmento azul y verde-azul postcocción que se utilizó para la decoración de una vasija de cerámica y una figurina de estilo Tolita-Tumaco del norte de Ecuador y sur de Colombia. Utiliza la difracción de Rayos X (DRX) y la microscopía electrónica de barrido (SEM) con la espectroscopía de energía dispersiva (EDS). Ofrece también una discusión sobre las implicancias del uso de este pigmento poco común en América del Sur.

El volumen concluye con un artículo de Izumi Shimada y Ursel Wagner sobre la manufactura de la cerámica negra de la costa norte de Perú, abarcando tanto la tecnología como la organización de su producción. Nos ofrecen un estudio holístico ejemplar que combina trabajos experimentales y análisis químicos y minerales. Aunque los autores no pudieron estar presentes en el simposio realizado en junio de 2018, el valor y la metodología integradora de este trabajo cierran muy bien esta publicación.

Agradecemos sinceramente la participación de todos los expositores, así como el envío de sus artículos para la publicación de estos dos números. 